Original Scientific Article

\title{
COMPARATIVE STUDY OF THE PHARMACOKINETICS OF INORGANIC AND ORGANIC IRON COMPOUNDS IN BROILER CHICKENS
}

\author{
Dimitrichka Dimitrova $^{1}$, Anna Arnaudova-Matey ${ }^{2}$, Petar Dilov², Geno Angelov², \\ Tandju Mehmedov'2, Toni Todorov², Denka Kushvalieva ${ }^{3}$, \\ Dimitrina Nikolova ${ }^{3}$, Valija Dilova ${ }^{4}$ \\ ${ }^{1}$ Department of Pharmacology, Animal Physiology and Physiological Chemistry, \\ Faculty of Veterinary Medicine, Trakia University, Stara Zagora, Bulgaria \\ ${ }^{2}$ Department of Non-infectious Diseases and Pharmacology, \\ Faculty of Veterinary Medicine, University of Forestry, Sofia, Bulgaria \\ ${ }^{3}$ Medical Diagnostic Laboratory "Chemalab-2003", Sofia, Bulgaria \\ 4 "Medica” Ltd., Sofia, Bulgaria
}

Received 21 October 2013; Received in revised form 12 December 2013; Accepted 8 January 2014

\begin{abstract}
The pharmacokinetics of ferrous methionate and ferrous sulphate was investigated in broiler chickens after intravenous injection and crop intubation. The iron compounds were injected intravenously in $v$. brachialis. After a 20-day "wash-out" period the ferrous methionate and ferrous sulphate were administered again by an elastic silicone tube into the crop. The serum concentrations of the iron were determined using a bioanalyser. Two pharmacokinetic approaches were used - compartmental and non-compartmental analysis. After i.v. injection we found statistically significantly longer and better distribution of the iron contained in the ferrous methionate compared to the ferrous sulphate. The $\mathrm{AUC}_{0 \rightarrow \infty}$ was statistically significantly higher in the ferrous methionate. In the alimentary tract of broiler chickens, ferrous methionate was absorbed more rapidly than ferrous sulfate. It was also distributed at a higher volume as compared to the ferrous sulfate.
\end{abstract}

Key words: pharmacokinetics, ferrous sulphate, ferrous methionate, chickens

\section{INTRODUCTION}

Iron plays an essential role in the occurrence and treatment of anemia. The atom of metallic iron in the ferrous state is incorporated into a porphyrin compound designated as iron protoporphyrin, or heme. Heme is then combined with a protein known as globin to from hemoglobin. Heme is also found in criterion enzyme systems concerned with oxygen exchange, such as the cytochrome system (1).

Corresponding author: Assoc. Prof. Dimitrichka Dimitrova, $\mathrm{PhD}$ E-mail address: dj.dimitrova.56@gmail.com

Present address: Department of Pharmacology, Animal Physiology and Physiological Chemistry, Faculty of Veterinary Medicine,

Trakia University, Stara Zagora-6000, Bulgaria

tel: +35942699 623; fax: +35942670624

Copyright: (C) 2014 Dimitrova D. This is an open-access article published under the terms of the Creative Commons Attribution License which permits unrestricted use, distribution, and reproduction in any medium, provided the original author and source are credited. Competing Interests: The authors have declared that no competing interests exist.

Available Online First: 13 January 2014

http://dx.doi.org/10.14432/j.macvetrev.2014.01.008
In iron-deficiency anemia, the red blood cells are smaller than normal and contain a decreased amount of hemoglobin. Iron-deficiency anemia can be very simply treated by oral administration of any one of several organic or inorganic iron compounds $(2,3)$. A wide variety of suitable therapeutic iron agents are available: reduced iron; soluble ferrous salts such as ferrous sulfate, ferrous chloride and ferrous glutamate; insoluble ferrous salts such as ferrous lactate, ferrous fumarate, and ferrous carbonate; and soluble ferric salts such as ferric ammonium citrate and ferric phosphate with sodium citrate. Unfortunately, ferrous lactate, ferrous chloride and ferrous sulphate are medicines used in the 1970 's and nowadays, only have historical significance in this respect. They are applied in the form of microelement food additives Soluble iron preparations (iron-dextran; iron-dextrin; iron-polysaccaride, peptonized iron) were administered by parenteral injection (4). The irondextran products were introduced in veterinary 
medicine in 1954 in England. The Imferon-50 was the first commercial product (5). In our country, extensive pharmacological studies with iron-dextran complexes were conducted in rabbits and pigs $(6,7)$.

In recent years, inorganic iron salts intended for the feed have been replaced by organic chelate complexes of iron with a single amino acid (US Patent \# 4.067.994 regarding Feric Methionine Complex) or by an acid complex (US Patent \# 5.698.724 regarding Iron Amino acid complex). It is assumed that chelates have pharmacological and technological advantage over inorganic salts. Unfortunately, there is insufficient scientific basis for comparison of organic iron complexes and inorganic salts (mainly the ferrous sulphate). As regards to the pharmacokinetics of ferrous methionate, the studies are quite insufficient, especially those in pigs (8). There is no information on the pharmacokinetics of iron compound in animals and especially in birds.

The purpose of this study was to determine the pharmacokinetics of iron after single intravenous and intraingluvial administration in broiler chickens of an inorganic compound - ferrous sulfate, and of an organic one - ferrous methionate. The other aim was to compare the pharmacokinetic parameters between ferrous sulfate and ferous methionate.

\section{MATERIALS AND METHODS}

\section{Animals, feeding and breeding}

Thirty-two broiler chickens-linear hybrid ROSS-IKOV, equal in number of both genders, weighing 1.140-1.420 kg were involved in the comparative pharmacological test. The birds were divided into two groups. The first group was treated with ferrous methonate and the second - with ferrous sulfate. Each group included 16 birds (8 male and 8 female) and was subject to a single intravenous and a single intraingluvial treatment. After a 20-day "wash-out" period of cleansing following i.v. injection, both iron compounds were administered intraingluvially by an elastic silicone tube into the crop.

We were breeding the birds in individual metal cages at an ambient temperature within the range of $20-22^{\circ} \mathrm{C}$ and air humidity $50 \%$. The broilers were fed with pelleted fodder for growing birds. They had free access to drinking water.

\section{Drugs}

Two iron products were used in the comparative pharmacokinetic test - ferrous sulphate $\left(\mathrm{Fe}_{2} \mathrm{SO}_{4} \cdot 7 \mathrm{H}_{2} \mathrm{O}\right)$ manufactured by the Merck company and ferrous methionate (synthesized and provided by the
Department of Organic Chemistry at the University of Chemical Technology and Metallurgy - city of Sofia, Bulgaria) produced by the interaction of geometionin and ferrous sulphate hydrate in a water environment.

\section{Experimental design}

We prepared working solutions of both products in a concentration of $1 \%$ with sterile distilled water. The solutions were needed for the intravenous injection and intraingluvial treatment of the birds. The organic chelate complex and inorganic salt of the iron were intravenously injected in a dose of $5 \mathrm{mg} \mathrm{Fe}{ }^{2+} / \mathrm{kg}$ body weight and in the intraingluvial administration in a dose of $10 \mathrm{mg} / \mathrm{kg}$ body weight. We prepared the working solutions ex tempore, immediately before the treatment of the broiler chickens. For the intravenous application, the solutions were heated in a water bath to a temperature of $37^{\circ} \mathrm{C}$ and slowly administered a bolus injection in the brachial vein ( $v$. brachialis) of the right wing. The intraingluvial administration of the ferrous methionate and ferrous sulphate aqueous solution was made directly into the crop through an elastic silicone tube and syringe after a $16 \mathrm{~h}$ diet. There was a 20-day "wash-out" period between the two modes of administration in each of the two groups for cleansing the chickens' body from the organic or inorganic iron product. We obtained the blood samples (each of $1 \mathrm{ml}$ ) in Eppendorf tubes with a cover at 0 (prior to the treatment), 0.17, 0.33, 0.50, $1,2,4,6,8,10,12$ and $24 \mathrm{~h}$ after the treatment. The obtained blood samples stayed for 2 hours at room temperature, so as the blood serum to be separated. For better and more complete separation of the blood serum we centrifuged the samples at $1500 \times g$ for $15 \mathrm{~min}$ in a refrigerated centrifuge. The serum of the birds from both groups was stored within $24 \mathrm{~h}$ at a temperature of $-20^{\circ} \mathrm{C}$ in a refrigerator.

The available amount of iron in the blood samples was determined in a specialised biochemical laboratory through bioanalyser (BS-200, Myndray Co.). The bioanalyser is a spectrophotometer which uses the direct ferrene method, at wavelength $\lambda=600 \mathrm{~nm}$. The principle of the method used was based on the fact that the ferric ions decompose in acidic environment under the influence of transferrin. The ascorbic acid, which was a component of the reducer used, reduced the ferric ions, which reacted with the chromogen (Ferren, 3 - (2-pyridyl) -5,-6-difuril-1, -2,-4-triazine disulphonate). This resulted in formation of a colour compound. 
Pharmacokinetics of inorganic and organic iron compounds in broiler

The pharmacokinetic parameters were determined by using two approaches - the compartmental method and non-compartanmental analysis (9), which required the use of specialised software pharmacokinetic programme TopFit, v.2.0. (10). The determination of the pharmacokinetic parameters was consistent with the criteria of Akaike (11) and the Schwartz's test (12).

The rate constants, characterising the phases of distribution and elimination $(\alpha, \beta)$; the rate constants of elimination from the central compartment $\left(\mathrm{k}_{\mathrm{el}}\right)$ and those of transition from the central to the peripheral compartment $\left(\mathrm{k}_{12}\right)$ and vice versa - from the periphery to the centre $\left(\mathrm{k}_{21}\right)$ were determined. Further determinations were made of the half-life time $\left(\mathrm{T}_{1 / 2 \alpha}\right)$ and elimination half-life $\left(\mathrm{T}_{1 / 2 \beta}\right)$; the mean residence time (MRT) and mean absorption time (MAT); the absorption half-life time $\left(\mathrm{T}_{1 / 2 \mathrm{abs}}\right)$; hidden time $\left(\mathrm{T}_{\text {lag }}\right)$; volume of distribution $\left(\mathrm{Vd}_{(\text {area })}\right)$ and that at steady state (Vss); volume of distribution in the central $\left(\mathrm{V}_{\mathrm{c}}\right)$ and tissue compartment $\left(\mathrm{V}_{\mathrm{t}}\right)$; total body clearance $\left(\mathrm{Cl}_{\mathrm{B}}\right)$; area under the serum concentrationtime curve from 0 to $\infty\left(\mathrm{AUC}_{0 \rightarrow \infty}\right)$; absorption rate constant $\left(\mathrm{k}_{\mathrm{abs}}\right)$; maximum serum concentration of the iron $\left(\mathrm{C}_{\max }\right)$ and the time to reach $\mathrm{C}_{\max }\left(\mathrm{T}_{\max }\right)$ and the absolute bioavailability $(\mathrm{F})$.
All pharmacokinetic parameters were calculated individually for each chicken and the values were expressed as mean values \pm standard error (SEM). We used the statistical computer programme Statistica 6.1. in the comparative pharmacokinetic study, as the results were processed through two different methods - parametric (one way ANOVA) and non-parametric (Mann-Whitney U test). The data obtained is presented in tabular form.

\section{Additional tests}

Some rheological indices of the ferrous sulphate and the ferrous methionate were determined, including determination of the following: bulk volume $\left(\mathrm{cm}^{2} / \mathrm{g}\right)$; bulk density $\left(\mathrm{g} / \mathrm{cm}^{2}\right)$; quiescence angle $\left({ }^{\circ}\right)$; flow rate $\left(\mathrm{g} / \mathrm{cm}^{2} . \mathrm{s}\right)$; loss during drying $(\%)$ and Hausner ratio, in order to establish which of both ferrous medicinal products intended for internal application would better and more uniformly distribute when mixed with the chickens' concentrated fodder.

\section{RESULTS}

The mean serum concentrations of iron in both drug products after intravenous and intraingluvial treatment of broiler chickens are presented in Table 1 and Fig. 1, respectively.

Table 1. Serum concentrations $(\mu \mathrm{mol} / \mathrm{l})$ of ferrous methionate (FM) and ferrous sulphate (FS), $1 \%$ solutions, after intraingluvial treatment and intravenous injection of broiler chickens

\begin{tabular}{|c|c|c|c|c|c|}
\hline \multirow[t]{2}{*}{ Time } & \multicolumn{2}{|c|}{$\begin{array}{c}\text { Ferrous } \\
\text { methionate }\end{array}$} & \multicolumn{2}{|c|}{$\begin{array}{l}\text { Ferrous } \\
\text { sulphate }\end{array}$} & \multirow[t]{3}{*}{ FM/FS } \\
\hline & \multicolumn{4}{|c|}{ Intraingluvial administration } & \\
\hline (h) & Mean & SEM & Mean & SEM & \\
\hline 0.17 & 24.538 & 1.405 & 23.400 & 1.309 & \\
\hline 0.33 & 27.138 & 2.099 & 25.175 & 1.378 & \\
\hline 0.50 & 26.788 & 2.422 & 27.075 & 1.392 & \\
\hline 1 & 25.175 & 2.195 & 26.113 & 1.923 & \\
\hline 2 & 23.888 & 2.001 & 25.800 & 2.224 & \\
\hline 4 & 21.188 & 1.828 & 25.450 & 2.270 & \\
\hline 6 & 19.275 & 1.595 & 22.100 & 1.164 & \\
\hline 8 & 16.988 & 1.552 & 17.650 & 1.015 & \\
\hline 10 & 14.613 & 1.345 & 15.475 & 0.793 & \\
\hline 12 & 13.575 & 0.989 & 13.113 & 0.985 & \\
\hline \multicolumn{6}{|c|}{ Intravenous injection } \\
\hline 0.17 & 185.025 & 12.238 & 143.713 & 19.612 & \multirow{7}{*}{$a_{1}$} \\
\hline 0.33 & 150.588 & 11.656 & 110.838 & 13.653 & \\
\hline 0.50 & 127.963 & 12.846 & 91.738 & 13.359 & \\
\hline 1 & 111.925 & 14.324 & 77.038 & 12.900 & \\
\hline 2 & 90.425 & 10.067 & 61.613 & 12.270 & \\
\hline 4 & 66.200 & 10.732 & 43.738 & 8.277 & \\
\hline 6 & 42.963 & 6.111 & 31.600 & 4.943 & \\
\hline 8 & 29.938 & 4.095 & 19.825 & 1.986 & \multirow{2}{*}{$u_{1} ; a_{1}$} \\
\hline 10 & 21.638 & 2.915 & 15.875 & 1.088 & \\
\hline 12 & 18.888 & 2.253 & 12.875 & 0.827 & $\mathbf{u}_{1} ; \mathbf{a}_{1}$ \\
\hline
\end{tabular}

Statistically significant differences compared to the ferrous sulphate; $\mathrm{u}_{1}$ - Mann-Whitney test at $\mathrm{p}<0.05$; $\mathrm{u}_{2}$ - at $\mathrm{p}<0.01 ; \mathrm{a}_{1}$ - ANOVA at $\mathrm{p}<0.05 ; \mathrm{a}_{2}$ - at $\mathrm{p}<0.01 ; \mathrm{a}_{3}$ - at $\mathrm{p}<0.001$. 


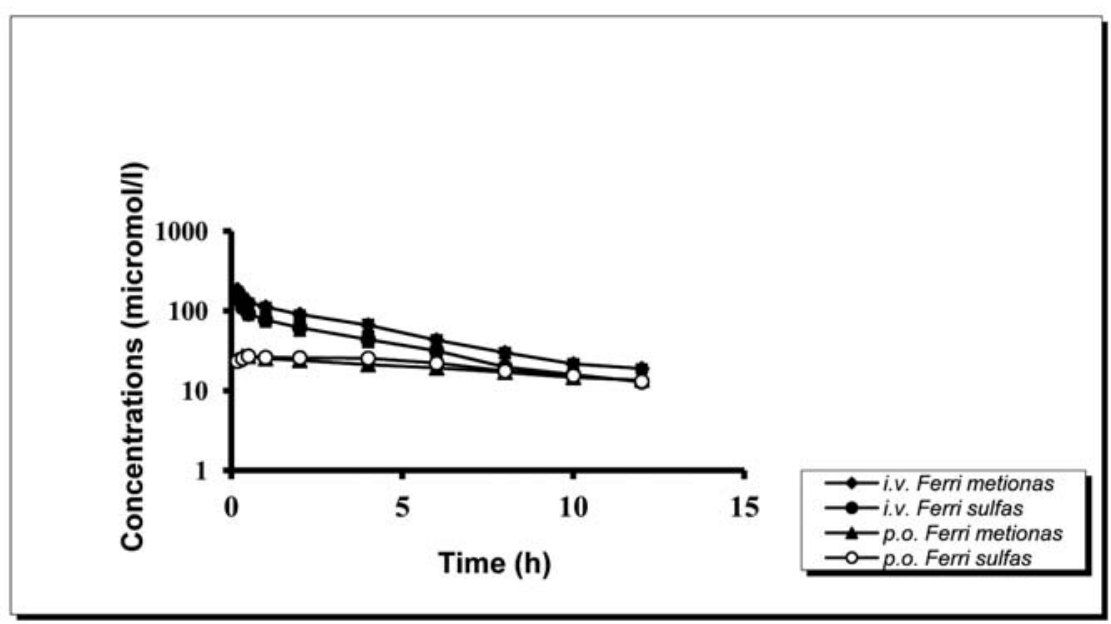

Figure 1. Serum concentrations of ferrous methionate and ferrous sulphate after single i.v. and p.o. (intraingluvial) application to broiler chickens

The tracing of the individual serum curves showed significant similarity. After i.v. injection of both $\mathrm{Fe}$ compounds (ferrous methionate and ferrous sulphate) the curves from the individual serum concentrations in all chickens corresponded to the two-compartmental pharmacokinetic model. Following intraingluvial administration the serum curves of both ferrous compounds in all broilers corresponded to the one-compartment open model.

The pharmacokinetic parameters of both drug products compared after intravenous and intraingluvial treatment are presented in Table 2 and Table 3 .

Table 2. Pharmacokinetic parameters of the ferrous methionate (FM) and ferrous sulphate (FS) after a single intraingluvial treatment of broiler chickens with $1 \%$ solution in a dose of $10 \mathrm{mg} / \mathrm{kg}$ body weight

\begin{tabular}{|c|c|c|c|c|c|c|}
\hline \multirow[t]{2}{*}{ Parameter } & \multirow[t]{2}{*}{ Units } & \multicolumn{2}{|c|}{$\begin{array}{c}\text { Ferrous } \\
\text { methionate }\end{array}$} & \multicolumn{2}{|c|}{$\begin{array}{l}\text { Ferrous } \\
\text { sulphate }\end{array}$} & \multirow[t]{2}{*}{ FM/FS } \\
\hline & & Mean & SEM & Mean & SEM & \\
\hline \multicolumn{7}{|c|}{ Compartmental analysis } \\
\hline $\mathbf{k}_{\text {abs. }}$ & $\mathbf{h}^{-1}$ & 13.2200 & 1.010 & 10.010 & 0.843 & \multirow[t]{2}{*}{$u_{1} ; a_{1}$} \\
\hline$T_{1 / 2 \beta}$ & h & 13.058 & 1.457 & 12.548 & 3.010 & \\
\hline$T_{1 / 2 \text { abs. }}$ & h & 0.0234 & 0.127 & 0.073 & 0.007 & $u_{1}$ \\
\hline MAT & h & 1.463 & 0.486 & 9.376 & 2.803 & \multirow[t]{3}{*}{$\mathbf{u}_{2} ; \mathbf{a}_{1}$} \\
\hline $\mathbf{T}_{\text {lag. }}$ & $\mathbf{h}$ & 0.0108 & 0.007 & 0.0025 & 0.001 & \\
\hline MRT & $\mathbf{h}$ & 21.310 & 3.744 & 18.938 & 2.104 & \\
\hline Vd $\mathbf{d}_{\text {(area) }}$ & l/ kg & 0.180 & 0.010 & 0.359 & 0.021 & \multirow[t]{5}{*}{$\mathbf{u}_{2} ; \mathbf{a}_{3}$} \\
\hline $\mathbf{A} \mathbf{U} \mathbf{C}_{0 \rightarrow \infty}$ & $\mu \mathrm{mol} \times \mathrm{h} / \mathrm{l}$ & 544.25 & 77.755 & 523.375 & 42.975 & \\
\hline $\mathbf{T}_{\max }$ & h & 0.450 & 0.046 & 0.543 & 0.039 & \\
\hline $\mathrm{C}_{\text {max }}$ & $\mu \mathrm{mol} / \mathrm{l}$ & 28.350 & 1.777 & 27.650 & 1.627 & \\
\hline $\mathbf{F}$ & $\%$ & 25.314 & 6.606 & 40.697 & 4.010 & \\
\hline \multicolumn{7}{|c|}{ Non-compartmental analysis } \\
\hline$T_{1 / 2 \beta}$ & $\mathbf{h}$ & 14.359 & 2.265 & 10.661 & 0.820 & \multirow{8}{*}{$a_{3}$} \\
\hline MRT & $\mathbf{h}$ & 20.663 & 3.279 & 14.838 & 1.308 & \\
\hline $\mathbf{A U C} \mathbf{C}_{0 \rightarrow \infty}$ & $\mu \mathrm{mol} \times \mathrm{h} / \mathbf{l}$ & 532.713 & 68.580 & 451.684 & 28.626 & \\
\hline AUMC & $\mu \mathrm{mol} \times \mathrm{h}^{2} / \mathrm{l}$ & 12325.00 & 3151.254 & 6848.5 & 944.00 & \\
\hline $\mathbf{C}_{\max }$ & $\mu \mathrm{mol} / \mathrm{l}$ & 28.938 & 2.028 & 28.588 & 1.812 & \\
\hline $\mathbf{T}_{\max }$ & $\mathbf{h}$ & 0.563 & 0.211 & 1.563 & 0.678 & \\
\hline МАT & $\mathbf{h}$ & 3.539 & 0.589 & 6.496 & 1.581 & \\
\hline $\mathbf{F}$ & $\%$ & 35.109 & 4.381 & 40.361 & 5.252 & \\
\hline
\end{tabular}

Statistically significant differences compared to the ferrous sulphate; $\mathrm{u}_{1}$ - Mann-Whitney test at $\mathrm{p}<0.05$; $\mathrm{u}_{2}$ - at $\mathrm{p}<0.01 ; \mathrm{a}_{1}-$ ANOVA at $\mathrm{p}<0.05 ; \mathrm{a}_{2}$ - at $\mathrm{p}<0.01 ; \mathrm{a}_{3}$ - at $\mathrm{p}<0.001$. 
Pharmacokinetics of inorganic and organic iron compounds in broiler

When conducting the rheological tests of the ferrous metionate and ferrous sulphate substances carried out, it was established that ferrous sulphate does not flow freely while the indices (quiescence angle and flow rate) cannot be directly determined. This result is most probably due to the high value concentration and dose, the serum concentrations of $\mathrm{Fe}^{+}$in the group of broiler chickens injected with ferrous methionate were higher in all time intervals during the blood sample taking than those found in the group injected with ferrous sulphate, in the presence of significance in the values at the 0.33 ,

Table 3. Pharmacokinetic parameters of the ferrous methionate (FM) and ferrous sulphate (FS) after a single i.v. injection of broiler chickens with $1 \%$ solution in a dose of $5 \mathrm{mg} / \mathrm{kg}$ body weight

\begin{tabular}{|c|c|c|c|c|c|c|}
\hline \multirow[t]{2}{*}{ Parameter } & \multirow[t]{2}{*}{ Units } & \multicolumn{2}{|c|}{$\begin{array}{c}\text { Ferrous } \\
\text { methionate }\end{array}$} & \multicolumn{2}{|c|}{$\begin{array}{l}\text { Ferrous } \\
\text { sulphate }\end{array}$} & \multirow[t]{2}{*}{ FM/FS } \\
\hline & & Mean & SEM & Mean & SEM & \\
\hline \multicolumn{7}{|c|}{ Compartmental analysis } \\
\hline$\alpha$ & $h^{-1}$ & 14.525 & 0.084 & 8.2168 & 2.061 & \multirow[t]{2}{*}{$u_{1} ; a_{2}$} \\
\hline $\boldsymbol{\beta}$ & $\mathbf{h}^{-1}$ & 0.0570 & 0.011 & 0.0991 & 0.021 & \\
\hline $\mathbf{K}_{12}$ & $\mathbf{h}^{-1}$ & 12.413 & 0.219 & 6.2944 & 1.890 & \multirow{3}{*}{$\mathbf{u}_{1} ; \mathbf{a}_{2}$} \\
\hline$K_{21}$ & $\mathbf{h}^{-1}$ & 0.4914 & 0.078 & 1.1003 & 0.355 & \\
\hline $\mathbf{K}_{\mathrm{el}}$ & $\mathbf{h}^{-1}$ & 1.6818 & 0.212 & 0.9380 & 0.311 & \\
\hline $\mathbf{K}_{12} / \mathbf{K}_{21}$ & - & 33.619 & 8.615 & 13.892 & 7.517 & $u_{1}$ \\
\hline$T_{1 / 2 \alpha}$ & h & 0.0477 & 0.0003 & 0.162 & 0.085 & \multirow[t]{2}{*}{$u_{1}$} \\
\hline$T_{1 / 2 \beta}$ & $\mathbf{h}$ & 8.978 & 1.367 & 11.190 & 3.957 & \\
\hline $\mathbf{T}_{\text {lag }}$ & $\mathbf{h}$ & 0.000105 & 0.000 & 0.026 & 0.011 & \multirow[t]{2}{*}{$\mathbf{u}_{2} ; \mathbf{a}_{1}$} \\
\hline MRT & $\mathbf{h}$ & 11.856 & 1.790 & 14.911 & 5.243 & \\
\hline $\mathbf{V}_{\mathrm{c}}$ & l/kg & 0.0028 & 0.0003 & 0.0230 & 7.214 & \multirow[t]{6}{*}{$u_{2} ; a_{1}$} \\
\hline$V_{t}$ & $\mathrm{l} / \mathrm{kg}$ & 0.090 & 0.025 & 0.075 & 0.020 & \\
\hline $\mathbf{V}_{\mathrm{ss}}$ & l/kg & 0.092 & 0.020 & 0.182 & 0.083 & \\
\hline $\mathbf{V} \mathbf{d}_{\text {(area) }}$ & l/kg & 0.104 & 0.021 & 0.107 & 0.021 & \\
\hline $\mathbf{A U C} \mathbf{C}_{\mathbf{0} \rightarrow \infty}$ & $\mu \mathrm{mol} \times \mathbf{h} / \mathbf{l}$ & 1268.38 & 187.07 & 693.125 & & \\
\hline $\mathrm{Cl}_{\mathrm{B}}$ & $\mu \mathrm{mol} / \mathrm{min} / \mathrm{kg}$ & 0.0045 & 0.0006 & 0.0080 & 0.0009 & \\
\hline \multicolumn{7}{|c|}{ Non-compartmental analysis } \\
\hline$T_{1 / 2 \beta}$ & $\mathbf{h}$ & 3.913 & 0.282 & 5.255 & 0.926 & \\
\hline MRT & h & 5.451 & 0.414 & 7.116 & 1.275 & \\
\hline $\mathbf{A U C} \mathbf{C}_{0 \rightarrow \text { last }}$ & $\mu \mathrm{mol} \times \mathrm{h} / \mathrm{l}$ & 660.389 & 68.453 & 447.608 & 63.774 & $u_{1} ; a_{1}$ \\
\hline $\mathbf{A U \mathbf { C } _ { 0 \rightarrow \infty }}$ & $\mu \mathrm{mol} \times \mathrm{h} / \mathbf{l}$ & 770.276 & 82.995 & 561.566 & 56.296 & $\mathrm{u}_{1}$ \\
\hline $\mathbf{A U M C}_{\mathbf{0} \rightarrow \infty}$ & $\mu \mathrm{mol} \times \mathbf{h}^{2} / \mathbf{l}$ & 4278.8 & 657.68 & 3912.500 & 650.136 & $\mathbf{a}_{3}$ \\
\hline $\mathbf{V}_{\mathrm{ss}}$ & $\mathrm{l} / \mathrm{kg}$ & 0.034 & 0.004 & 0.067 & 0.014 & $a_{1}$ \\
\hline $\mathrm{Cl}_{\mathrm{B}}$ & $\mu \mathrm{mol} / \mathrm{min} / \mathrm{kg}$ & 0.108 & 0.016 & 0.156 & 0.012 & $\mathbf{u}_{1} ; \mathbf{a}_{1}$ \\
\hline
\end{tabular}

Statistically significant differences compared to the ferrous sulphate; $\mathrm{u}_{1}$ - Mann-Whitney test at $\mathrm{p}<0.05$;

$\mathrm{u}_{2}$ - at $\mathrm{p}<0.01 ; \mathrm{a}_{1}$ - ANOVA at $\mathrm{p}<0.05 ; \mathrm{a}_{2}$ - at $\mathrm{p}<0.01 ; \mathrm{a}_{3}$ - at $\mathrm{p}<0.001$.

of the loss during drying index $(37 \%)$. The results for ferrous methionate are best determined with respect to the rheological indices - quiescence angle $\left(30.65^{\circ}\right)$, flow rate $\left(2.25 \mathrm{~g} / \mathrm{cm}^{2} . \mathrm{s}\right)$ and Hausners ratio (1.14). They provide grounds to determine the flow behavior of ferrous methionate as good.

\section{DISCUSSION}

In the intravenous injection of the broiler chickens with both iron compounds in the same
8 and 12 hour after the intravenous bolus injection of the drug products used (Table 1).

In the intraingluvial administration similar trend in the serum concentrations was found in the first time intervals during the blood sample taking, corresponding to the phase of absorption, without any statistical significance in the differences found (Table 1). After intraingluvial application of both iron compound, the iron levels in the blood serum of ferrous methionate were lower than these of ferrous sulfate, which is probably due to the higher 
percentage of binding to the serum proteins, and better and more rapid tissue penetration (in tissue peripheral compartment) (see pharmacokinetic parameters $\mathrm{K}_{12}$ and $\mathrm{K}_{12} / \mathrm{K}_{21}$ in Table 3 ).

After the intravenous injection of the birds, statistically significant differences in the values characterising the phase of distribution of both iron products were observed. They may be determined, as follows: significantly higher values of the " $\alpha$ " phase in ferrous methionate compared to those of ferrous sulphate; faster penetration of iron from the central to the peripheral compartment in the organic chelate complex (ferrous methionate) compared to that of the inorganic salt (ferrous sulphate), which was demonstrated by the significantly higher values of the hybrid rate constant $\mathrm{k}_{12}$; statistically significantly slower return of the iron ions from the peripheral to the central compartment in ferrous methionate, as evidenced by the significantly lower values of $\mathrm{k}_{21}$ in ferrous methionate compared to those observed in ferrous sulphate; statistically significantly shorter halflife time $\left(\mathrm{T}_{1 / 2 \alpha}\right)$ in ferrous methionate compared to that of ferrous sulphate; significantly higher values of the parameter $\mathrm{A}$ and the ratio $\mathrm{k}_{12} / \mathrm{k}_{21}$ in ferrous methionate compared to those of the inorganic salt of the iron (Table 3 ).

There were no statistically significant differences between the two iron compounds and certain parameters, which did not depend on the model, such as biological half-life $\left(\mathrm{T}_{1 / 2 \beta}\right)$, mean residence time (MRT) and $\mathrm{AUC}_{0 \rightarrow \infty}$, set according to the compartmental method and the non-compartanmental analysis in the intravenous bolus injection of ferrous methionate and ferrous sulphate of broiler chickens (Table 2 and Table 3). In the birds injected with ferrous methionate the values of $T_{1 / 2 \beta}$ and MRT were significantly higher in both pharmacokinetic methods compared to those observed after the intravenous injection of ferrous sulphate. The longer exposure to the iron after injection of the organic chelate complex was probably due to its high ability to bind to the serum proteins. The higher content of iron in the chickens injected with ferrous methionate may be explained by the fact that the organic complex of $\mathrm{Fe}^{2+}$, compared to the inorganic salt (ferrous sulphate), had a higher molecular weight (426.0) than that of ferrous sulphate (278.02). Probably another significant reason for the different retention time of $\mathrm{Fe}^{2+}$ in the blood after intravenous application was the ability of ferrous sulphate to pass easily into an ionisation state before connecting to the serum proteins and tissue protein structures, since the ionised substances were excreted more rapidly from the body through the kidneys.

Due to the significantly higher serum concentrations of iron after intravenous application of ferrous methionate compared to those observed after the injection of ferrous sulphate, the values of $\mathrm{AUC}_{0 \rightarrow \infty}$ and $\mathrm{AUMC}_{0 \rightarrow \infty}$ in the group treated with ferrous methionate were statistically significantly higher than those observed after the application of the inorganic salt of the iron. We found that after the intravenous injection of the organic chelate complex (ferrous methionate), $\mathrm{Fe}^{2+}$ was distributed in significantly lower volume compared to that in the birds injected with inorganic salt (ferrous sulphate), which was evidenced by the values of Vd, Vss and Vc (Table 3).

In the intraingluvial treatment of the broiler chickens with ferrous methionate or ferrous sulphate, the absorption half-life time $\left(\mathrm{T}_{1 / 2 \mathrm{abs}}\right)$ values and those of the MAT parameter showed that the ferrous methionate was statistically significantly absorbed in a shorter time by the digestive tract of the birds compared to the inorganic salt used, at $\mathrm{p}$ $<0.05$. This mode of administration of both iron compounds showed that ferrous methionate stayed longer in the broiler chicken body, as evidenced by the values of the biological half-life $\left(\mathrm{T}_{1 / 2 \beta}\right)$ and those of the mean residence time (MRT) determined through both pharmacokinetic methods. There was a similar trend in other pharmacokinetic parameters AUC and AUMC, which showed better distribution of the organic chelate complex compared to the inorganic salt of the iron, at $\mathrm{p}<0.001$ for AUMC (Table 2).

The intraingluvial administration of the organic chelate complex of the iron and the inorganic salt in the birds showed that the maximum serum concentrations $\left(\mathrm{C}_{\max }\right)$ were higher in ferrous methionate and reached much faster $\left(\mathrm{T}_{\max }\right)$ after the administration of both drug products.

There are no studies about the pharmacokinetics of the iron in broiler chickens and therefore we may do a comparison with the data set for other animal species and humans. The information about the pharmacokinetics of the iron in pigs after p.o. administration of iron methionate at a dose of 20 $\mathrm{mg} / \mathrm{kg}$ is of interest in the literature. The maximum serum concentrations, which we determined in the chickens by using the two pharmacokinetic methods, were significantly lower than those determined by Petrichev M. (8) in pigs treated with iron methionate $\mathrm{C}_{\max }=104,50 \mu \mathrm{mol} / \mathrm{L}$, which we could explain with 
the five times higher dose $(50 \mathrm{mg} / \mathrm{kg})$ used in the pigs. The ratio in the values of $\mathrm{T}_{\max }$ observed in the broiler chickens was similar, compared to those in the pigs determined by Petrichev M. (8) - $\mathrm{T}_{\max }=2.67$. The biological half-life $\left(\mathrm{T}_{1 / 2 \beta}\right)$ and the mean residence time (MRT) after intravenous injection in broiler chickens had lower values compared to those in the pigs $\left(\mathrm{T}_{1 / 2 \beta}=9.41 \mathrm{~h}\right.$ and MRT $\left.=13.56 \mathrm{~h}\right)$ after intravenous injection with ferrous methionate (8).

The specified rheological indices of the ferrous methionate powder mixture would provide its uniform distribution when mixed with the birds' fodder. The ferrous methionate smaller particles have larger surface within the powder mixture, which in turn would result in a greater surface of contact between the ferrous chelate complex and the birds' fodder.

A modern pharmacokinetic profile of the ferrous sulphate and ferrous methionate in broiler chickens has been created, which is a good basis for demonstrating the benefits of the organic complexes (chelates) of iron compared to its inorganic salts.

Moreover, the advantages of some pharmacokinetic parameters $\quad\left(\mathrm{AUC}_{0 \rightarrow \infty}, \mathrm{t}_{1 / 2 \beta}\right.$, $\mathrm{C}_{\max }$ and $\mathrm{T}_{\max }$ ) established in the organic complex compared to the inorganic salt of iron suppose better bioactivity after entering the body of the broiler chickens.

The rheological studies of ferrous methionate and ferrous sulphate have shown that the fluidity of the organic chelate complex is significantly better than that of the ferrous sulphate, which suggests its better homogenization with the bird and pig fodder.

\section{REFERENCES}

1. Geisser, P., Burckhardt, S. (2011). The Pharmacokinetics and Pharmacodynamics of Iron preparations. Pharmaceutics, 3(1): 12-33.

2. Egli, A. K., Franstad, T., Gramingen, D. (1998). The effect of per oral administration of aminoacid chelated iron to pregnant sows in prevention sow and piglet anemia. Acta Veterinaria Scandinavica 39(1): 77-87.
3. Andrews, N. C. (1999). Disorders of iron metabolism. The New England Journal of Medicine 341, 1986-1995.

4. Kalantaz-Zadeh, K. E., Steja, E., Miller, J. E., Nissenson, A. R. (2009). Intravenous iron versus erythropoiesis-stimulating agents: Friends or foes in treating chronic kidney disease anemia? Advances in Chronic Kidney Disease 16, 143-151.

5. Browrilie, W. M. (1955). The Tretment of Piglet Anaemia. Veterinary Record 67, 350-354.

6. Antonov, S. I. (1971). Study of the iron metabolism in relation to the anaemia in the mammal pigs. $\mathrm{Ph}$. D. Thesis, Faculty of Veterinary Medicine, Sofia, Bulgaria (in Bulgarian).

7. Dilov, P. (1976). Pharmacological properties and biological standardisation of the ferro-dextran preparations. Ph. D. Thesis, Faculty of Veterinary Medicine, Sofia, Bulgaria (in Bulgarian).

8. Petrichev, M. H. (2006). Study of the toxicity, bioavailability and antianaemic effect of the methionine iron complex fodder additive in laboratory animals and pigs. Ph. D. Thesis, Faculty of Veterinary Medicine, University of Forestry, Sofia, Bulgaria.

9. Gibaldi, M., Perrier, D. (2007). Noncompartmental Analysis Based on Statistical Moment Theory, In: James Swarbrick (ed.), Pharmacokinetics, Revised and Expanded, 2 ed., (pp. 409-419). Informa-Healthcare, USA Inc.

10. Heinzel, G., Woloszak, R., Thomann, P. (1993). Topfit. Version 2.0., Pharmacokinetic and Pharmacodynamic Data Analysis System for PC, Gustav Ficher, Stuttgart, Jena, New York

11. Yamaoka, K., Nakagawa, T., Uno, T. (1978). Application of Akaike's Information Criterion (AIC) in the evaluation of linear pharmakcokinetic equations. Journal of Pharmacokinetics and Biopharmaceutics 6, 166-17.

12. Swartz, G. (1978). Estimating the dimension of a model. Annals of Statistics 6, 461-464. 